\title{
Integration of theoretical and the empirical deformations by KALMAN-Filtering in the North Anatolia Fault Zone
}

\author{
F. Poyraz and E. Gülal \\ Yildiz Technical University, Istanbul, Turkey
}

Received: 10 April 2007 - Revised: 22 October 2007 - Accepted: 23 October 2007 - Published: 22 November 2007

\begin{abstract}
Earthquakes occur in regions with intense seismic activities and cause life and property losses. Predicting earthquakes, identifying deformations and decreasing earthquake effects have been major subjects for scientists, engineers, and authorities. One of the theories used for identifying location changes during an earthquake is the elastic half-space model. Recently, the Global Navigation Satellite System has also been used for the same purpose.

In this work, the deformations caused by the earthquake across the Marmara Region on 17 August 1999 are determined by theoretical and empirical methods. The data retrieved from the half elastic-space model and GPS measurements were filtered with the Kalman filter technique. The difference between the half elastic-space model and GPS measurements increases in the area close to the fault zone. The study results showed that the fault line is actually not a line but an area within the earthquake region which can be called a deformation zone. To increase the efficiency of the Kalman filter, differences between the theoretical and empirical models were modeled using the Kriging technique. Using the theoretical model which was calibrated by the Kriging griding, forecast values were retrieved for deformations occurred across the earthquake region after the earthquake.
\end{abstract}

\section{Introduction}

The North Anatolia Fault Zone (NAFZ), which borders the Anatolia/Eurasia tectonic plate originating from Karlova and ending in the Aegean Sea with approximately $1500 \mathrm{~km}$ length, is defined as a right lateral strike slip fault zone (Fig. 1).

Scientific researches reveal that NAFZ have a major impact on earthquakes in Turkey. Under the GPS Observa-

Correspondence to: F. Poyraz

(fpoyraz@gmail.com) tion Network Project (MAGNET), which was funded by a number of public organizations and foundations, a network of observation stations was installed in the Marmara region to be operated permanently. After the Izmit earthquake, GPS observations were obtained at about 50 point locations across the region. To determine the seismic risk in the region, various studies were carried out using GPS observations (Bürgmann et al., 2002; Feigl et al., 2002; Reilinger et al., 2000; Ergintav et al., 2002). Reilinger et al. (2000) calculated the post-earthquake linear position change ratios with 75 days point coordinates and their covariance by using the weighted least square adjustment method. Ergintav et al. (2002) determined post-earthquake deformation ratios as a function of time using GPS observations obtained from the available stations for 298 days.

Using the retrieved information, the position changes during and after earthquake, and the distribution of changes along the fault were determined. It was observed that the changes caused by the Izmit earthquake had a maximum effect on the Gölcük province and the western and eastern parts of Sapanca. The slip values were found as $5.7 \mathrm{~m}$ and $4.7 \mathrm{~m}$ at the west and east of the earthquake center, respectively (Reilinger et al., 2000; Ergintav et al., 2002).

\section{Empirical approach (geodetic GPS measurements)}

GPS measurement technique is commonly used in engineering surveying. Milimeter level accuracy can be achieved by GPS measurement method depending on measurement and process strategies. GPS is also used in many areas of geologist (Bürgmann et al., 2002; Feigl et al., 2002; Reilinger et al., 2000; Ergintav et al., 2002).

This study presents an examination of position displacements of 6 points within the city of Sakarya shown in Figs. 12. The city was one of the most affected regions during the Izmit and Düzce earthquakes. Additionally, 6 local

Published by Copernicus Publications on behalf of the European Geosciences Union. 


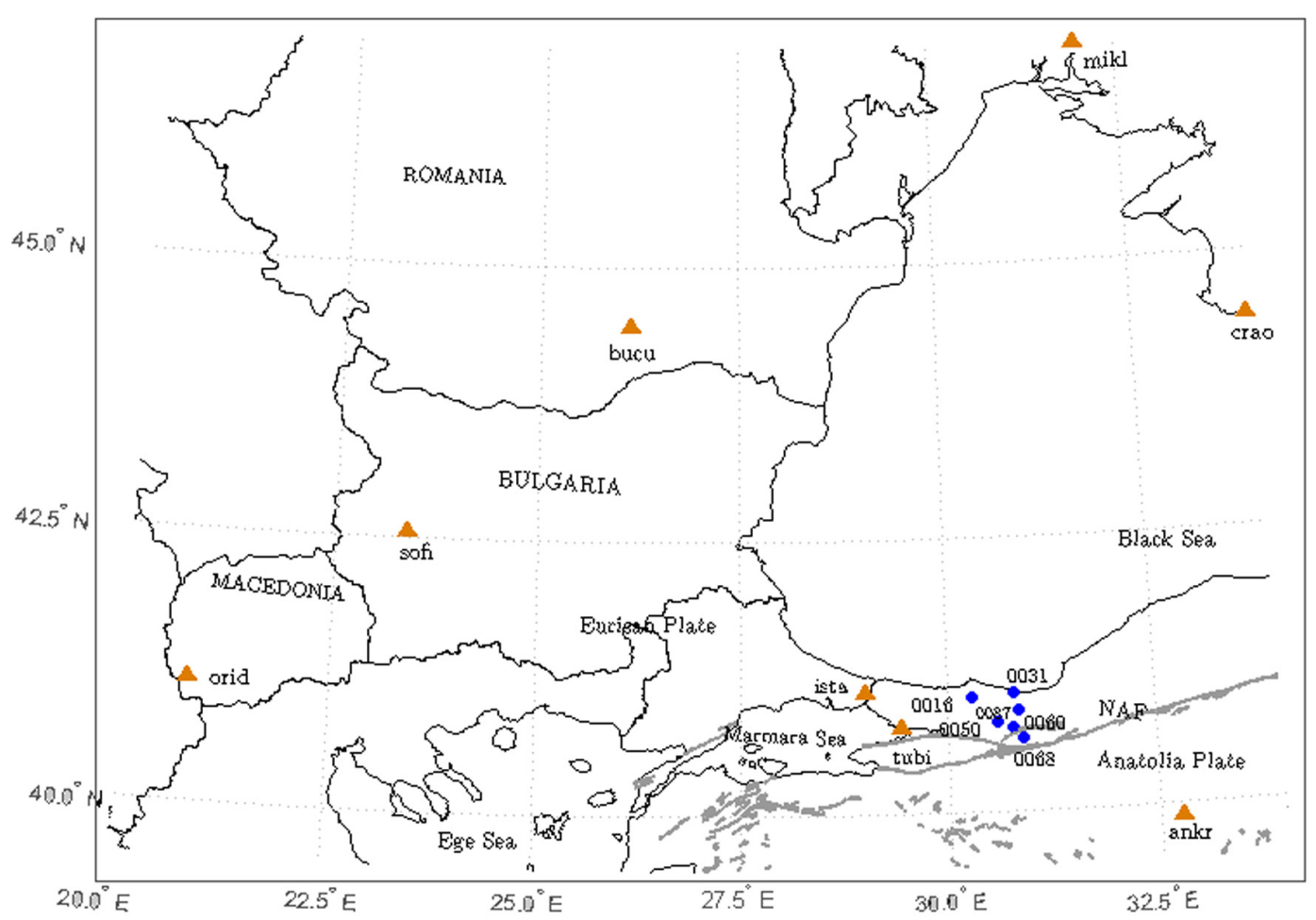

Fig. 1. The North Anatolia Fault Zone in the Marmara region. $\triangle$ IGS and EUREF GPS stations, $\bullet$ Local GPS stations (NAF: North Anatolia Fault).

Table 1. Point displacements obtained from GPS observations.

\begin{tabular}{lrrr}
\hline Points & $d x_{\mathrm{GPS}}(\mathrm{m})$ & $d y_{\mathrm{GPS}}(\mathrm{m})$ & $d z_{\mathrm{GPS}}(\mathrm{m})$ \\
\hline Ankr & 0.039 & -0.008 & -0.020 \\
Tubi & 0.067 & -0.080 & -0.030 \\
0087 & 0.429 & -0.488 & -0.127 \\
0068 & 0.999 & 0.052 & -0.344 \\
0060 & -0.273 & 0.247 & 0.089 \\
0050 & 0.578 & -0.576 & -0.120 \\
0031 & 0.276 & -0.250 & -0.120 \\
0016 & 0.344 & -0.264 & -0.081 \\
\hline
\end{tabular}

points were selected from the measurement values which are suitable for crustal deformation work. When choosing the points, long time GPS observations (for example; 4-10 h) in both epoch conditions were taken into consideration. In the evaluation of GPS data the selected global stations were utilized. These stations are near to the region and their velocity rates are low. (BAHR, GRAZ, KIT3, MATE, NICO, BUCU, SOFI, TUBI and ANKR). Some of these points were not shown in Fig. 1 due to the scale problem.

In the study, the long time observations by the General Directorate of Land Registry and Cadastre of Turkey (TKGM) within the study region and contours were utilized. The data cover 1998 pre-earthquake and 2000 post-earthquake observations. Using GAMIT GPS processing software, the data were processed as 2 epochs: year 1998 days 240-254 and year 2002 days 140-207. The ITRF 2000 coordinate system was used in the study. The point numbers were labeled with 4 digit numbers as required by the IGS station standards. The strategy in GAMIT GPS processing software was adapted from Herring (1997), and King and Bock (1997) with consideration of the most appropriate model to the type of data. Table 1 shows the values of point displacements $\left(d x_{\mathrm{GPS}}, d y_{\mathrm{GPS}}\right.$, and $\left.d z_{\mathrm{GPS}}\right)$ between pre-earthquake and post-earthquake times obtained from the process of GPS observations. The vector forms of the point displacements are displayed in Fig. 2.

\section{Theoretical approach (elastic half-space model)}

A number of studies were performed till today about applying the elastic dislocation theory to earth's crust (Aki and Richards, 1980; Cohen, 1999; Okada, 1985; Press, 1965; Stekeete, 1958). For simplifying the problem, earth's crust is assumed as half-space instead of whole-space both in analytic and in numeric methods. Half-space can be considered as a block that normal stress and traction is zero in one of the whole-space surfaces. Assuming the earth's surface as a half-space that normal stress and traction is zero, is decreased 


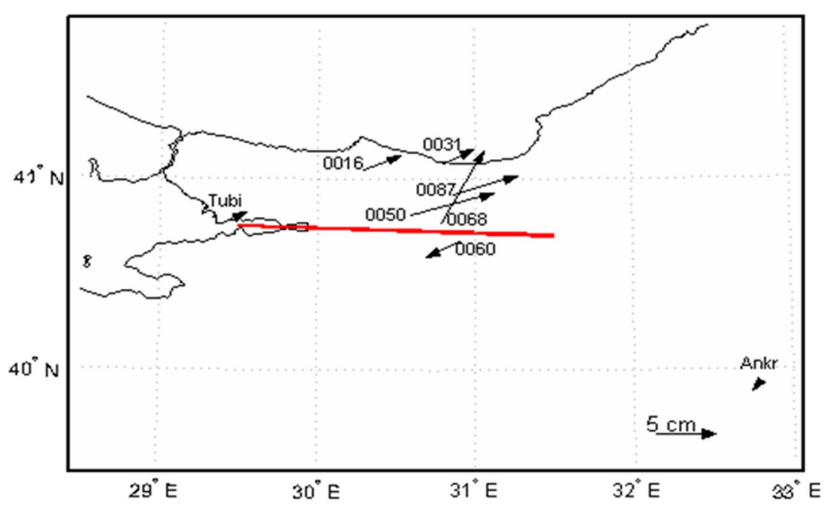

Fig. 2. Horizontal position movements obtained from GPS baseline processing (NAFZ was shown with red line).

the calculation problem 3 times. Although whole-space is almost never used in geology, earth mechanics and modeling the deep structures are the samples of the application areas of the approach.

We follow Okada's notation, as listed in Table 2. The dislocation formulation is given in closed analytic form by Okada (1985). Accordingly, the displacement field $\boldsymbol{u}_{i}\left(x_{1}, x_{2}, x_{3}\right)$ due to a dislocation $\boldsymbol{\Delta} \boldsymbol{u}_{j}\left(\xi_{1}, \xi_{2}, \xi_{3}\right)$ across a surface $\Sigma$ in an isotropic medium is given by:

$\boldsymbol{u}_{i}=\frac{1}{F} \iint_{\sum} \Delta u_{j}\left[\lambda \delta_{j k} \frac{\partial u_{i}^{n}}{\partial \xi_{n}}+\mu\left(\frac{\partial u_{i}^{n}}{\partial \xi_{k}}+\frac{\partial u_{i}^{k}}{\partial \xi_{j}}\right)\right] v_{k} d \sum$

where $\delta_{j k}$ Kronecker delta, $\lambda$ and $\mu$ are Lamé's coeffients, $v_{k}$ is the direction cosine of the normal to surface element $d \sum$, and the summation convention applies. The term $u_{i}^{j}$ is the $i$ th component of the displacement at $\left(x_{1}, x_{2}, x_{3}\right)$ due to the $j$ th direction point force of magnitude $F$ at $\left(\xi_{1}, \xi_{2}, \xi_{3}\right)$.

For obtaining the displacement area which is caused by quadrangle area, from the displacement area which was caused by point source, analytical equations derived from Eq. (1) must be solved by integration depending on length $(L)$ and width $(W)$ of the fault plane (Press, 1965).

Integral $\left(\int_{x}^{x-L} d \xi \int_{p}^{p-W} d \eta\right)$ can be expressed in Eq. (2) below. Here, $x$ and $p$ represent the coordinates of the fault plane and $d \xi$ and $d \eta$ stand for the displacement functions of the point source according the elastic half-space model depending on coordinates on the fault plane.

$f(\xi, \eta)$

$=f(x, p)-f(x, p-W)-f(x-L, p)+f(x-L, p-W)$

Analytical equations which were derived from Eq. (1) for fault plane are given Eqs. (3)-(13). It is possible to express the plane displacements $\left(u_{x}, u_{y}, u_{z}\right)$ caused by the components of the slip vector $\left(U_{1}, U_{2}\right)$ by calculating the integral of Eq. (2). Thus, the derived lateral and vertical pulse equation is given below (Okada, 1985).
Table 2. Notations for the formulas which were used for defining the Elastic Half-Space model (formulas for 1-15).

\begin{tabular}{lll}
\hline Symbol & Quantity & Units \\
\hline$\delta$ & Dip of fault (from horizontal) & degrees \\
$\lambda, \mu$ & Elastic (Lamé) coefficients & Pa s \\
$y^{\prime}, d^{\prime}$ & Coordinates of the fault plane km & \\
$\xi, \eta, q$ & Coordinates of the first point of the fault & $\mathrm{km}$ \\
& plane & \\
$R$ & Distance between first point of the fault & $\mathrm{km}$ \\
& plane and the origin & \\
$X$ & Coordinate of the point on the fault direc- & $\mathrm{km}$ \\
& tion & \\
$\boldsymbol{U}_{i}$ & Slip vector on fault (left-lateral, up-dip, & $\mathrm{mm}$ \\
& tensile) & \\
$\boldsymbol{u}_{i}$ & Displacement vector at surface & $\mathrm{mm}$ \\
$M_{0}$ & Seismic moment & $\mathrm{N} \mathrm{m}$ \\
$M$ & Seismic Moment Magnitude & - \\
$L$ & Length of fault patch along strike & $\mathrm{km}$ \\
$W$ & Width of fault patch along dip & $\mathrm{km}$ \\
$\alpha$ & Strike of fault (azimuth taken clockwise & $\mathrm{degrees}$ \\
& from North) & \\
$D$ & Locking depth & $\mathrm{km}$ \\
\hline
\end{tabular}

The reader is referred to Okada (1985) for the complete set of equations, including a discussion of previous derivations. Lateral Pulse

$$
\begin{aligned}
& u_{x}=-\frac{U_{1}}{2 \pi}\left[\frac{\xi q}{R(R+\eta)}+\tan ^{-1} \frac{\xi \eta}{q R}+I_{1} \sin \delta\right] \\
& u_{y}=-\frac{U_{1}}{2 \pi}\left[\frac{y^{\prime} q}{R(R+\eta)}+\frac{q \cos \delta}{R+\eta}+I_{2} \sin \delta\right] \\
& u_{z}=-\frac{U_{1}}{2 \pi}\left[\frac{d^{\prime} q}{R(R+\eta)}+\frac{q \sin \delta}{R+\eta}+I_{4} \sin \delta\right]
\end{aligned}
$$

Vertical Pulse

$$
\begin{aligned}
& u_{x}=-\frac{U_{2}}{2 \pi}\left[\frac{q}{R}+I_{3} \sin \delta \cos \delta\right] \\
& u_{y}=-\frac{U_{2}}{2 \pi}\left[\frac{y^{\prime} q}{R\left(R+x^{\prime}\right)}+\cos \delta \tan ^{-1} \frac{x^{\prime} \eta}{R+\eta}-I_{1} \sin \delta \cos \delta\right] \\
& u_{z}=-\frac{U_{2}}{2 \pi}\left[\frac{y^{\prime} q}{R(R+\xi)}+\sin \delta \tan ^{-1} \frac{\xi \eta}{q R}-I_{5} \sin \delta \cos \delta\right]
\end{aligned}
$$

Equations between Eq. (9)-(13) are the auxiliary formulas which were used for calculating the strike-slip ans dip-slip.

$$
\begin{aligned}
& I_{1}=\frac{\mu}{\lambda+\mu}\left[\frac{-1}{\cos \delta} \frac{\xi}{R+d^{\prime}}\right]-\frac{\sin \delta}{\cos \delta} I_{5} \\
& I_{2}=\frac{\mu}{\lambda+\mu}[-\ln (R+\eta)]-I_{5}
\end{aligned}
$$


Table 3. Fault model parameters used in the elastic half-space model.

\begin{tabular}{lrrrrrrrrr}
\hline & $\lambda\left(^{\circ}\right)$ & $\varphi\left({ }^{\circ}\right)$ & $\alpha\left(^{\circ}\right)$ & $D(\mathrm{~km})$ & $\delta\left(^{\circ}\right)$ & $L(\mathrm{~km})$ & $W(\mathrm{~km})$ & $S S(\mathrm{~m})$ & $D S(\mathrm{~m})$ \\
\hline Izmit (\#1) & 29.41 & 40.68 & 86.29 & -0.08 & -90.12 & 97.34 & 16.03 & 2.80 & 0.28 \\
Izmit (\#2) & 30.67 & 40.69 & 71.36 & -0.10 & -63.80 & 24.50 & 18.74 & 1.64 & 0.54 \\
Düzce & 31.08 & 40.76 & 88.14 & 0.00 & -51.35 & 28.45 & 17.20 & 3.76 & 0.76 \\
\hline
\end{tabular}

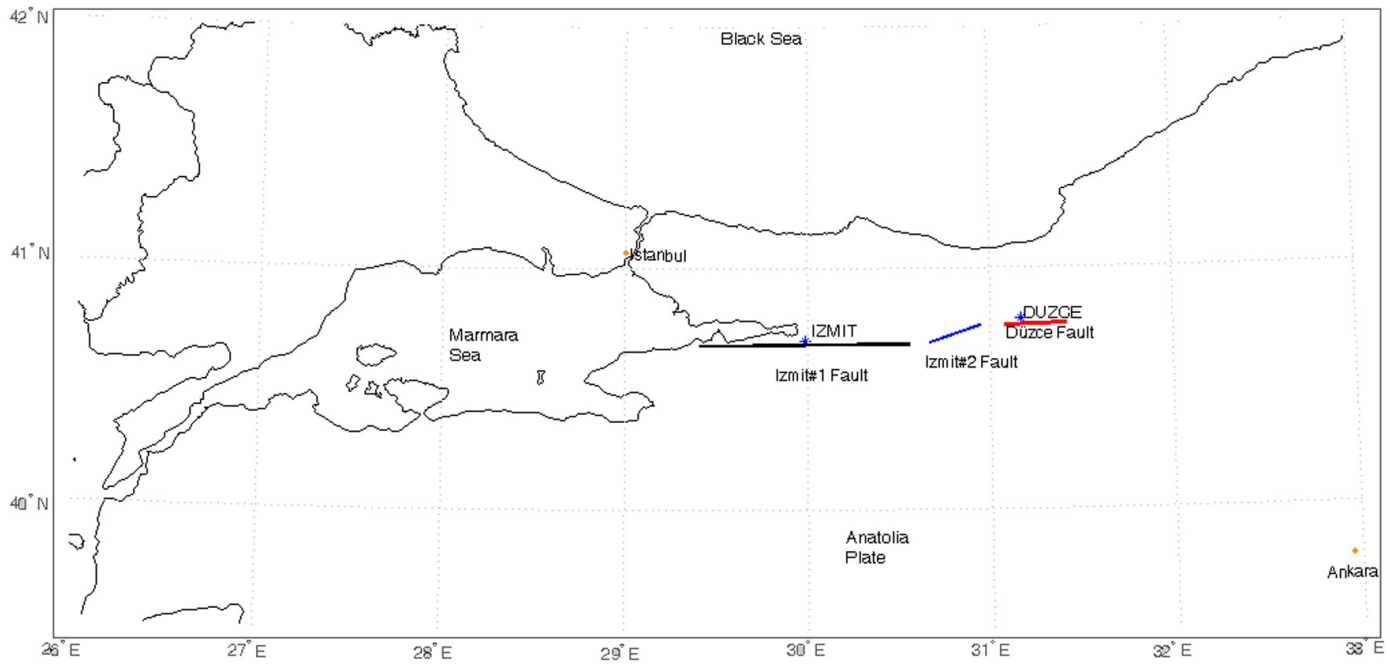

Fig. 3. Centers of the Izmit $\left(40.70^{\circ} \mathrm{N}, 29.98^{\circ} \mathrm{E}\right)$ and Düzce $\left(40.77^{\circ} \mathrm{N}, 31.15^{\circ} \mathrm{E}\right)$ Earthquakes and 3 parts faults (Izmit \#1, Izmit \#2 and Düzce) which were used in elastic half-space model in this study.

$$
\begin{aligned}
& I_{3}=\frac{\mu}{\lambda+\mu}\left[\frac{1}{\cos \delta} \frac{y^{\prime}}{R+d^{\prime}}-\ln (R+\eta)\right]+\frac{\sin \delta}{\cos \delta} I_{4} \\
& I_{4}=\frac{\mu}{\lambda+\mu} \frac{1}{\cos \delta}\left[\ln \left(R+d^{\prime}\right)-\sin \delta \ln (R+\eta)\right] \\
& I_{5}=\frac{\mu}{\lambda+\mu} \frac{2}{\cos \delta} \tan ^{-1} \frac{\eta(X+q \cos \delta)+X(R+X) \sin \delta}{x^{\prime}(R+X) \cos \delta}
\end{aligned}
$$

Using the elastic half-space model, displacement vectors during the earthquake can be obtained very close to the actual displacements (Okada, 1985). If the fault plane geometry, which causes differences in geodetic point coordinates and displacements are known, surface displacements can be calculated using the elastic half-space model. The forward and inverse models can be employed to calculate the fault parameters.

The elastic model parameters are used to determine the co-seismic displacements at any point caused by the earthquake (i.e., forward modeling). The estimated parameters are optimized by comparing with the measured values using a trial and error procedure. The Izmit and Düzce earthquakes were studied by national and international organizations such as MAGNET, a joint project by the General Command of Mapping-Turkey and the German Federal Agency for Cartography and Geodesy (IFAG) to determine the characteris- tics of the fault formed by the earthquakes. Using the measurements, displacements occurred on the earth surface were calculated determined partly.

In this study, the NAFZ data obtained during the previous earthquakes were also utilized for building-up the fault parameters. Using the old and new values, inverse modeling was applied and different solutions about the type of the fault were reached (Bürgmann et al., 2002; Reilinger et al., 2000). It was observed that displacements obtained from the forward modeling, which was developed with the fault plane geometry solutions, are different from each other. The study results indicate that the fault geometry solutions given by Reilinger et al. (2000) better represent the displacements determined by GPS observations. In the elastic half-space model application, a fault with 3 parts named as Izmit (\#1), Izmit (\#2) and Düzce was selected (Table 3). The co-seismic displacements were determined utilizing the fault parameters at these locations obtained from the GPS and InSAR database of the Turkish General Commandership of Mapping (Ayhan et al., 2001, and Reilinger et al., 2000). In this study, 3 pieced fault was used with elastic half-space model. These parts were named as Izmit (\#1), Izmit (\#2) and Düzce fault parts in this section (Fig. 3). Co-seismic displacements were calculated by using the fault parameters in these 3 parts. These fault parameters were gathered from 


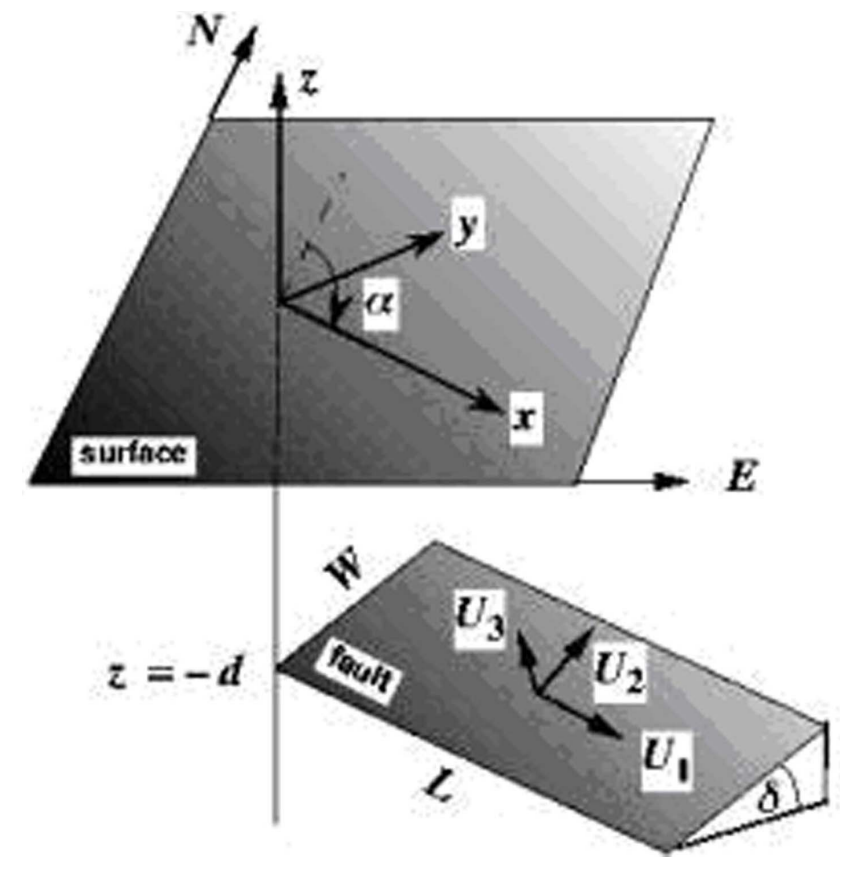

Fig. 4. Fault geometry and symbols. The strike $(\alpha)$ and dip $(\delta)$ angles are shown. The slip vector $\boldsymbol{U}=\left[U_{1}, U_{2}, U_{3}\right]$ represents the movement of the hanging wall with respect to the foot wall oriented such that positive $U_{1}$ is left-lateral strike slip, positive $U_{2}$ is thrusting dip slip, and $U_{3}$ is tensile slip.

(Ayhan et al., 2001; Reilinger et al., 2000), GPS and INSAR data of General Command of Mapping.

The dislocation may be either a point source or a rectangular fault patch of finite dimension $L$ by $W \mathrm{~km}$. In either case, the slip on the fault plane is a vector with three components, $U_{1}, U_{2}, U_{3}$ in $\mathrm{mm}$ (Fig. 4).

The origin of the fault patch lies at its lower left-hand corner when viewed from the hanging wall. The coordinates of the origin are $E, N$, and $d$, taken positive East, North, and down. To transform the $(\mathrm{x}, \mathrm{y})$ coordinate system given by Okada (1985) we rotate by the strike (azimuth) of the fault, in degrees clockwise from North. To avoid ambiguity, an observer facing along the strike should see the fault dip at $d$ degrees to his right. This set of 10 parameters comprises one line of the input "faults" file described below.

$\lambda$ and $\varphi$ are the longitude and latitude of the first point respectively, $\alpha$ is the strike angle, $D$ is the depth of fault plane, $\delta$ is the dip angle, $L$ is the length of the fault plane, $W$ is the width of fault plane, $S S\left(U_{1}\right)$ is the strike slip, $D S$ $\left(U_{1}\right)$ is the dip slip in Table 3.

Fault parameters were recalculated with "trial and error", and thus the ideal parameter values were obtained. The displacement values retrieved from fault parameters were compared against the displacements calculated from GPS observations in order to obtain the ideal parameter values. When calculating these parameters, as a second criterion, fault pa-
Table 4. Earthquake intensity and standard deviation values.

\begin{tabular}{lccc}
\hline & $M_{w}$ & Std. Deviation (m) & $M_{0}(\mathrm{Nm})$ \\
\hline Izmit (\#1) & 7.41 & 0.04 & $13.03 \times 10^{19}$ \\
Izmit (\#2) & 6.91 & 0.03 & $2.31 \times 10^{19}$ \\
Düzce & 7.16 & 0.02 & $5.49 \times 10^{19}$ \\
\hline
\end{tabular}

Table 5. Point movements obtained from the elastic half-space model.

\begin{tabular}{lrrr}
\hline Points & $d x_{\text {Theoric }}(\mathrm{m})$ & $d y_{\text {Theoric }}(\mathrm{m})$ & $d z_{\text {Theoric }}(\mathrm{m})$ \\
\hline Ankr & -0.019 & 0.014 & 0.008 \\
Tubi & 0.520 & -0.377 & -0.052 \\
0087 & 0.410 & 0.165 & -0.006 \\
0068 & 0.647 & 0.246 & -0.265 \\
0060 & -0.319 & -0.164 & 0.032 \\
0050 & 0.682 & 0.250 & -0.067 \\
0031 & 0.226 & 0.097 & -0.015 \\
0016 & 0.251 & 0.063 & -0.014
\end{tabular}

rameters of seismic moment values were obtained and they were compared with those by the Kandilli Observatory of Bogazici University for correction purposes.

If Eq. (14) is investigated, it can be seen that area of the fault plane is calculated by multiplying the slip distance and shear module. Area of the fault plane is simply the multiplication of the fault length $L$ by the fault width $W$. Slip distance is the square root of the sum of $U_{1}$ (Strike Slip) and $U_{2}$ (Dip Slip) squares. Typical values for $\mu$ in the Earth's crust range from 30-36 GPa. Since the shear modulus $\mu$ generally varies with area properties, it is taken $30 \mathrm{GPa}$ as calculated by Bürgmann et al. (2002), Aktuğ (2003) and Çakır (2003) for this particular area.

The seismic moment and its magnitude are calculated using the formulas by Kanomari (1977) given below:

Seismic moment;

$M_{o}=L W \sqrt{U_{1}^{2}+U_{2}^{2}} \mu$

Seismic Moment Magnitude;

$M_{w}=\frac{2}{3} \log \left(M_{0}\right)-6.0$

Earthquake intensity can be estimated by calculating the seismic moment which is chosen as input for deformation analysis and estimation of the intensity distributions. Fault parameters are used to calculate the seismic moment value. Fault parameters were calculated by using trial and error to obtain the best fitting parameters. The seismic moment can be calculated more accurately if the fault parameters (Table 3 ) exist in more measurement group (like GPS measurements, InSAR values). Best fitting parameter values were investigated 
by comparing the movement values derived from these fault parameters and movement values derived from GPS measurements. Also seismic moment value was compared with the results of the Eqs. (14) and (15), and Izmit $\left(M_{w}=7.4\right)$ and Düzce $\left(M_{w}=7.2\right)$ values. Best fitting fault parameters were calculated iteratively. Seismic moment, amplitude of the seismic moment and the standard deviations were tabulated in Table 4.

The displacements of 8 points used in this study were determined using Dislocater software program (Aktuğ, 2003). The program calculates a single component of the displacement field resulting from a finite or point-source dislocation buried in an elastic half space. The input parameters are fault position, depth, length, width, strike, dip, and three components of slip. The outputs are displacement components in the form of an ASCII list or a rectangular array of binary integers. The program also provides partial derivatives of the displacement component with respect to all 10 input parameters. Point movement values retrieved using the elastic half-space model is given in Table 3.

Table 5 shows the point movements which were obtained using the fault parameters in Table 3 as input values.

Table 5 and Fig. 1 display that the differences between the measured and predicted values are relatively large near the fault zone but they get relatively small away from the fault zone. This is due mainly to the fact that the fault in the earthquake region is actually not a line but a zone. This is a deformation zone and, therefore, different effects such as liquefaction, local subsidence and heterogeneous crust geology should be taken into account when using elastic models for surface displacements near a fault zone (Aktuğ, 2003). Since the GPS measurements were performed 3 years after the Marmara earthquake of 1999, during this period additional post-seismic and inter-seismic deformations (up to $2.5 \mathrm{~cm}$ per year), which elastic half- space models are not able to capture, should be considered when evaluating these differences. In this study, the Kalman filtering and Kriging method instead of the elastic half-space models were applied to predict deformations caused by post-seismic and other activities.

\section{Integration of theoretical and the empirical approach by KALMAN-Filtering}

The Kalman filtering method, which is used in different areas of engineering science (Cannon et al., 1986; Schwarz et al., 1989; Donellan et al., 1993; Lu and Lachapelle, 1994), is one of the methods used in deformation analysis Pelzer (1986). Developments in measurement techniques caused new evaluation models and different new software usages in deformation analysis as well. Today, most important purposes of engineering measurements have become to analyze the behaviors of bridges, dams, towers and other objects which are exposed to landslides and earthquakes. To describe the relation between deformation and its cause, mathematical and statistical analysis methods are employed. The Kalman filtering technique can be called as one of the deformation analysis techniques.

Deformations occur due to differences in forces and generally can change depending on time. Mathematical models developed to determine the deformations are simplified physical facts and they usually depend on forces or time (Kuhlmann and Pelzer, 1997). Deformations are analyzed by kinematic, static or dynamic models depending whether a deformation is defined by time and velocity (kinematic), force (static), or time and force (dynamic). If there is no movement on points, quasi-static models are used for this puprpose (Welsch and Heunecke, 1999).

System and measurement equations are combined in a well-known algorithm for estimating an optimal state vector $\boldsymbol{x}$, containing parameters to describe deformation behavior (Welsch et al., 2000). Due to recursive algorithm - working from epoch $k$ to $k+1-$ the Kalman filter is applicable in real time. The mathematical model of a linear system in discontinuous time is given below (Kalman, 1960; Gelb, 1974; Salzmann, 1993):

$\boldsymbol{x}(k+1)=\mathbf{T}(k) \boldsymbol{x}(k)+\mathbf{B}(k) \mathbf{u}(k)+\mathbf{C}(k) \mathbf{w}(k)$

$\boldsymbol{x}(k)$ : State vector

$\mathbf{T}(k)$ : Transition matrix

$\mathbf{u}(k)$ : Control input, regulating variable

$\mathbf{B}(k)$ : Input coupling matrix

$\mathbf{w}(k)$ : System noise

$\mathbf{C}(k)$ : System noise coupling

Also, state vector $\boldsymbol{x}$ is related linearly to measurements $\boldsymbol{l}$ with design matrix A. $\varepsilon$ is the measurement noise:

$\boldsymbol{l}(k+1)=\mathbf{A}(k+1) \boldsymbol{x}(k+1)+\varepsilon(k+1)$

System Eq. (16) is derived from the dynamic system. Therefore, it corresponds to the dynamic model. It does not exist in the kinematic model $\mathbf{B}(k) \mathbf{u}(k)$, because no reasons for deformation are considered in the model. It is also missing in the static model $\mathbf{T}(k) \boldsymbol{x}(k)$, because the object immediately responds to changes of input. There is no memory. In the identity model there are no causes for deformations, and transition matrix simplifies to identity matrix I (Pelzer, 1988; Kuhlmann, 2003).

In this study, a static deformation model was used. In the model, object movements are expressed with only forces affected by the object. Since the time component is not considered the transition matrix is $\mathbf{T}=\mathbf{I}$ (Pelzer, 1988).

The equations used in the Kalman filtering during prediction (Eqs. 18-19) and filtering phases (Eqs. 20-23) are as follows

$\overline{\boldsymbol{x}}_{k}=\hat{\boldsymbol{x}}_{k-1}+\mathbf{B}_{k, k-1} \mathbf{u}_{k-1}+\mathbf{C}_{k, k-1} \mathbf{w}_{k}$

$\mathbf{Q}_{\bar{x} \bar{x}, k}=\mathbf{Q}_{\hat{x} \hat{x}, k-1}+\mathbf{B}_{k, k-1} \mathbf{Q}_{u u, k-1} \mathbf{B}_{k, k-1}^{T}+\mathbf{Q}_{w w, k-1}$ 


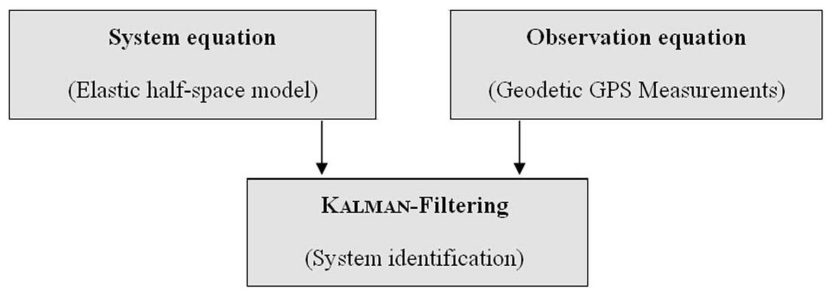

Fig. 5. Integration by Kalman-Filtering.

$\mathbf{Q}_{d d, k}=\mathbf{D}_{k}=\mathbf{Q}_{l l, k}+\mathbf{A}_{x, k} \mathbf{Q}_{\bar{x} \bar{x}, k} \mathbf{A}_{x, k}^{T}$

$\mathbf{K}_{k}=\mathbf{Q}_{\bar{x} \bar{x}, k} \mathbf{A}_{x, k}^{T} \mathbf{D}_{k}^{-1}$

$\hat{\boldsymbol{x}}_{k}=\overline{\boldsymbol{x}}_{k}+\mathbf{K}_{k}\left(\boldsymbol{l}_{k}-\mathbf{A}_{x, k} \overline{\boldsymbol{x}}_{k}\right)$

$\hat{\boldsymbol{x}}_{k}=\overline{\boldsymbol{x}}_{k}+\mathbf{K}_{k} \quad \boldsymbol{d}_{k}$

$\mathbf{Q}_{\hat{x} \hat{x}, k}=\mathbf{Q}_{\bar{x} \bar{x}, k}-\mathbf{K}_{k} \mathbf{D}_{k} \mathbf{K}_{k}^{T}$

Before starting the deformation analysis, all possible errors have to be determined. In the Kalman Filtering the most important equation is the one to retrieve the innovation vector (Eq. 24) (Salzmann, 1990)

$\boldsymbol{d}_{k}=\boldsymbol{l}_{k}-\mathbf{A}_{x, k} \overline{\boldsymbol{x}}_{k}$

In the Kalman filtering technique, with the help of global test, it is determined whether the state vector predicted for $t_{k}$ time is correct or not. Measurement and system equations should be compatible both mathematically and statistically. If the predicted state vector and measurements are compatible, the zero hypotheses are constructed to identify whether this innovation is significant. If the constructed $H_{0}$ is invalid, an investigation should be done about the discrepancy between predicted state vector and measurements. The reason of the discrepancy can be the predicted state vector and/or the measurements. Outlier detection process is first applied. If no outlier is detected an error is searched in the system equation and localization process for model errors is applied.

In this study, system equation was formed by the elastic half-space model and the observation equation was formed by the geodetic GPS measurements. Thus, theoretical and empirical approach integration was applied with the Kalman filtering technique (Fig. 5).

The cause of the deformation $u_{k}$ has an effect on object points. The effect on object points which describes the object geometry is expressed with $\mathbf{B}_{k, k-1} \mathbf{u}_{k-1}$ terms of the system equation. In Eq. (18), the input value in $\mathbf{B}_{k, k-1} \mathbf{u}_{k-1}$ which is to be modeled will be retrieved from co-seismic point movements retrieved from elastic half-space model. For this purpose, the following equation is employed

$\overline{\boldsymbol{x}}_{1}=\mathbf{T}_{0,1} \hat{\boldsymbol{x}}_{0}+\boldsymbol{d}_{\text {Theoric }}+\mathbf{w}_{0}$

As the system discrepancy can not be predicted it is assumed that $E\{w\}=0$. In Eq. (25), the transition matrix $(\mathbf{T}=\mathbf{I})$ is a
Table 6. Point movements determined from the Kalman Filtering application.

\begin{tabular}{lrrrrrr}
\hline Points & $d x(\mathrm{~m})$ & $\sigma_{x}(\mathrm{~mm})$ & $d y(\mathrm{~m})$ & $\sigma_{y}(\mathrm{~mm})$ & $d z(\mathrm{~m})$ & $\sigma_{z}(\mathrm{~mm})$ \\
\hline Ankr & -0.019 & 4.7 & 0.014 & 3.2 & 0.008 & 4.4 \\
Tubi & 0.150 & 4.9 & -0.011 & 3.5 & 0.034 & 4.7 \\
0087 & 0.370 & 6.8 & -0.467 & 4.9 & -0.099 & 6.6 \\
0068 & 0.940 & 12.6 & 0.074 & 8.3 & -0.316 & 12.7 \\
0060 & -0.331 & 7.9 & 0.268 & 5.3 & 0.117 & 7.8 \\
0050 & 0.519 & 6.9 & -0.555 & 5.3 & -0.092 & 6.7 \\
0031 & 0.216 & 6.1 & -0.228 & 4.4 & -0.093 & 5.8 \\
0016 & 0.285 & 6.7 & -0.242 & 4.6 & -0.052 & 6.4 \\
\hline
\end{tabular}

unit matrix and $\boldsymbol{d}_{\text {Theoric }}$ is the point movement retrieved from elastic half-space model as shown in Table 5. After adding the values retrieved from the elastic half space model $\hat{\boldsymbol{x}}_{0}$ (the state vector for year 1998 - before the earthquake), the current state vector $\overline{\boldsymbol{x}}_{1}$ was retrieved.

Equation (19) is used for determining the stochastic part of the system equation. in this equation $\mathbf{Q}_{\hat{x} \hat{x}, k-1}$ was derived from standard deviations of the pre-earthquake GPS results which were formed by free network adjustment. $\mathbf{Q}_{w w, k-1}$ is defined as failure matrix which contains the unmodeled errors. $\mathbf{B}_{k, k-1} \mathbf{Q}_{u u, k-1} \mathbf{B}_{k, k-1}^{T}$ is the variance-covariance matrix of displacements which were derived with elastic halfspace model. This term is calculated from Eq. (26) by variance propagation theory. For calculating the variance matrix $\left(\boldsymbol{\Sigma}_{u u, k-1}\right)$, which defines the earthquake intensity, standard deviations of the seismic moment amplitude were used. By dividing the displacement values, which were derived from elastic half-space model, to seismic moment values $\mathbf{F}$ matrix was obtained. Thus, the effect of the earthquake intensity on the point displacements was calculated with variance propagation theory.

$\boldsymbol{\Sigma}_{u u, k-1}=\mathbf{F} \boldsymbol{\Sigma}_{m m} \mathbf{F}^{T}$

Variance matrix has been calculated using Eq. (26) which also affects the system. The summation of pre-earthquake variance matrix of points, system disorder variance matrix and values retrieved from Eq. (26) is equal to predicted status vector variance matrix in Eq. (19). The variance matrix of system equalization is retrieved in this way.

Observation equality of the filter process was built with the GPS measurements performed in the study area. Equation (20) was retrieved using reform vector variance matrix, post-earthquake GPS values variance matrix and predicted status variance matrix. Position changes retrieved from integration of theoretical and the empirical approach by Kalman filtering are given in Table 6.

The filtered values obtained from the half space model seemed to be very close the actual values. Especially, the movements at the Tubi point are so close to the movements retrieved from GPS measurements. The values obtained from 

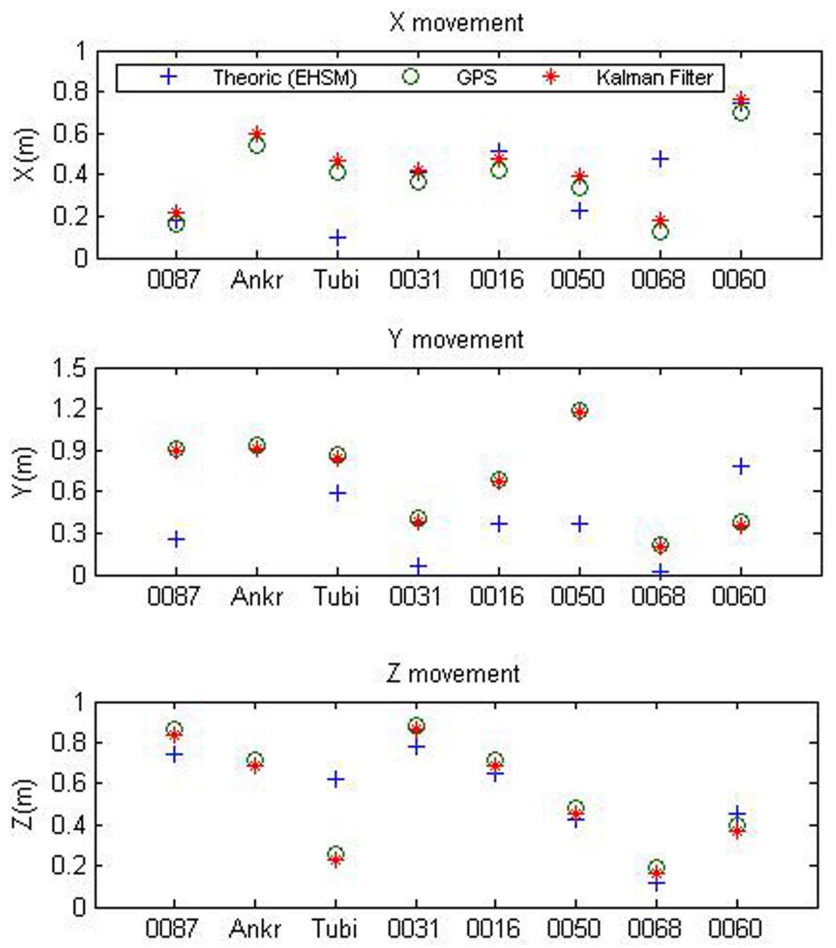

Fig. 6. Comparing the coordinates in $\mathrm{x}, \mathrm{y}$ and $\mathrm{z}$ directions retrieved from the elastic half-space model (EHSM), Kalman filtering and GPS processing.

the elastic half-space model, the Kalman filtering and GPS processing are shown in Fig. 6.

In Sect. 3, it was shown that co-seismic effects due to point displacement can be modeled by elastic half-space models. The evaluation of GPS data showed (see Fig. 6) that postseismic and other tectonic effects can exist in addition to coseismic effects. The Kalman filtering can roughly detect such effects using innovation vector $\boldsymbol{d}$. As shown in Eq. (24) matrix $\mathbf{A} \overline{\boldsymbol{x}}_{k}$ is computed by multiplying prediction state vector with design matrix $\mathbf{A}$. These values are subtracted from observed $\boldsymbol{l}_{k}$ values to determine post-earthquake effects. During global test and localization process post-seismic effects are determined at points with relatively large effects, especially near the fault zone. The differences between GPS data and the elastic half-space model outputs were decreased by the Kalman filtering technique as shown in Fig. 6.

Applying the Kalman filtering to TUBI values (0068 in $\mathrm{x}, 0087$ in $\mathrm{y}, 006$ in y directions) predicted by the elastic half-space model decreased errors producing closer values to post-earthquake coordinate data. Assuming that the prediction equation is correct the results were obtained by increasing variances in the system noise matrix of points near the fault zone during the localization. This was actually accomplished by the use of GPS data during the filtering process.
Table 7. Calculated difference values for 8 points.

\begin{tabular}{lrrr}
\hline Points & $\bar{d} x_{\text {diff }}(\mathrm{m})$ & $\bar{d} y_{\text {diff }}(\mathrm{m})$ & $\bar{d} z_{\text {diff }}(\mathrm{m})$ \\
\hline Ankr & 0.058 & -0.022 & -0.028 \\
Tubi & -0.453 & 0.297 & 0.022 \\
0087 & 0.019 & -0.653 & -0.121 \\
0068 & 0.352 & -0.194 & -0.079 \\
0060 & 0.046 & 0.411 & 0.057 \\
0050 & -0.104 & -0.826 & -0.053 \\
0031 & 0.050 & -0.347 & -0.105 \\
0016 & 0.093 & -0.327 & -0.067 \\
\hline
\end{tabular}

Table 8. Difference values retrieved after Kriging gridding.

\begin{tabular}{lrrr}
\hline Points & $\hat{d} x_{\text {diff }}(\mathrm{m})$ & $\hat{d} y_{\text {diff }}(\mathrm{m})$ & $\hat{d} z_{\text {diff }}(\mathrm{m})$ \\
\hline Ankr & 0.047 & -0.007 & -0.029 \\
Tubi & -0.451 & 0.301 & 0.012 \\
0087 & 0.027 & -0.542 & -0.110 \\
0068 & 0.256 & -0.190 & -0.058 \\
0060 & 0.035 & 0.235 & 0.034 \\
0050 & -0.015 & -0.732 & -0.042 \\
0031 & 0.046 & -0.342 & -0.110 \\
0016 & 0.070 & -0.316 & -0.060 \\
\hline
\end{tabular}

\section{Determining the displacement with measurement and estimation values}

In this section, some possible effects along with co-seismic and post-seismic effects are removed by gridding the differences between measurement and model prediction values. For this purpose, the pre-earthquake and post-earthquake positions, and retrieved displacement values $\boldsymbol{d}_{\mathrm{GPS}}$ in the previous section are utilized to determine displacements at any desired point via interpolation of co-seismic and post-seismic displacements.

First, using Izmit and Duzce earthquake fault plane parameters given by Ayhan et al. (2001) and Reilinger et al. (2000) and using the Dislocator software, co-seismic movements were calculated via the elastic half-space model proposed by Okada (1985) and $\boldsymbol{d}_{\text {theoric }}$ at measurement points was computed. During this, fault plane models, two for Izmit and one piece for Düzce, were used as given in Ayhan et al. (2001) and Reilinger et al. (2000). The relevant fault geometry and dislocation values taken from these studies are shown in Table 3 .

In this section, post-earthquake effects which can not be determined with EHSM were calculated with Eq. (27). The differences between the measured and theoretical displacements at the points (co-seismic + post-seismic) were 
Table 9. Point movements obtained from calibrated theoretical model.

\begin{tabular}{lrrr}
\hline Points & $d x_{\text {Calibre-Theoric }}$ & $d y_{\text {Calibre-Theoric }}$ & $d z_{\text {Calibre-Theoric }}$ \\
& $(\mathrm{m})$ & $(\mathrm{m})$ & -0.021 \\
\hline Ankr & 0.028 & 0.007 & 0.040 \\
Tubi & 0.069 & -0.076 & -0.116 \\
0087 & 0.437 & -0.377 & -0.323 \\
0068 & 0.903 & 0.055 & 0.065 \\
0060 & -0.284 & 0.071 & -0.109 \\
0050 & 0.667 & -0.482 & -0.125 \\
0031 & 0.272 & -0.246 & -0.074 \\
0016 & 0.321 & -0.253 & \\
\hline
\end{tabular}

Table 10. Movement values resulting from adopted Kalman Filtering.

\begin{tabular}{lrrrrrr}
\hline Points & $\begin{array}{r}d x \\
(\mathrm{~m})\end{array}$ & $\begin{array}{r}\sigma_{x} \\
(\mathrm{~mm})\end{array}$ & $\begin{array}{r}d y \\
(\mathrm{~m})\end{array}$ & $\begin{array}{r}\sigma_{y} \\
(\mathrm{~mm})\end{array}$ & $\begin{array}{r}d z \\
(\mathrm{~m})\end{array}$ & $\begin{array}{r}\sigma_{z} \\
(\mathrm{~mm})\end{array}$ \\
\hline Ankr & 0.035 & 3.4 & 0.002 & 2.3 & -0.019 & 2.0 \\
Tubi & 0.011 & 3.6 & -0.009 & 2.4 & 0.030 & 2.0 \\
0087 & 0.427 & 5.4 & -0.381 & 6.2 & -0.125 & 4.1 \\
0068 & 0.899 & 16.1 & 0.059 & 6.9 & -0.336 & 8.8 \\
0060 & -0.278 & 6.1 & 0.073 & 8.1 & 0.086 & 5.0 \\
0050 & 0.665 & 11.2 & -0.479 & 6.8 & -0.117 & 4.1 \\
0031 & 0.271 & 4.7 & -0.242 & 3.4 & -0.121 & 3.6 \\
0016 & 0.336 & 5.1 & -0.256 & 3.3 & -0.079 & 4.0 \\
\hline
\end{tabular}

determined by Eq. (27) and the results are given in Table 7.

$\overline{\boldsymbol{d}}_{\mathrm{diff}}=\boldsymbol{d}_{\mathrm{GPS}}-\boldsymbol{d}_{\text {Theoric }}$

The Kriging gridding technique was applied using the calculated differences. With this technique a continuous plane is achieved between the measurement points using the trend in measurements. Considering the characteristics of points, some parameters can be changed (variogram model and an-isotropy) to increase the plane accuracy in this method (Cressie, 1990). This method identifies the grid edges considering structure of the data. The main difference of the Kriging method from others is the variogram model. The main point of variogram model is that two close points have more common characteristics than two far points. By this method, residuals were removed by placing the points to the grid corners. The difference values ( $\left.\overline{\boldsymbol{d}} x_{\text {diff }}, \overline{\boldsymbol{d}} y_{\text {diff }}, \overline{\boldsymbol{d}} z_{\text {diff }}\right)$ in Table 7 were employed in the Kriging method and the results are shown ( $\left.\hat{\boldsymbol{d}} x_{\text {diff }}, \hat{\boldsymbol{d}} y_{\text {diff }}, \hat{\boldsymbol{d}} z_{\text {diff }}\right)$ in Table 8 .

As shown in Eq. (28), movement values retrieved from the elastic- half space model ( $\left.\boldsymbol{d}_{\text {theoretical }}\right)$ were added to the Kriging model results $\left(\hat{\boldsymbol{d}}_{\text {diff }}\right)$. And the $\boldsymbol{d}$ difference values are shown in Table 9.

$\boldsymbol{d}_{\text {Calibre-Theoric }}=\hat{\boldsymbol{d}}_{\text {diff }}+\boldsymbol{d}_{\text {Theoric }}$
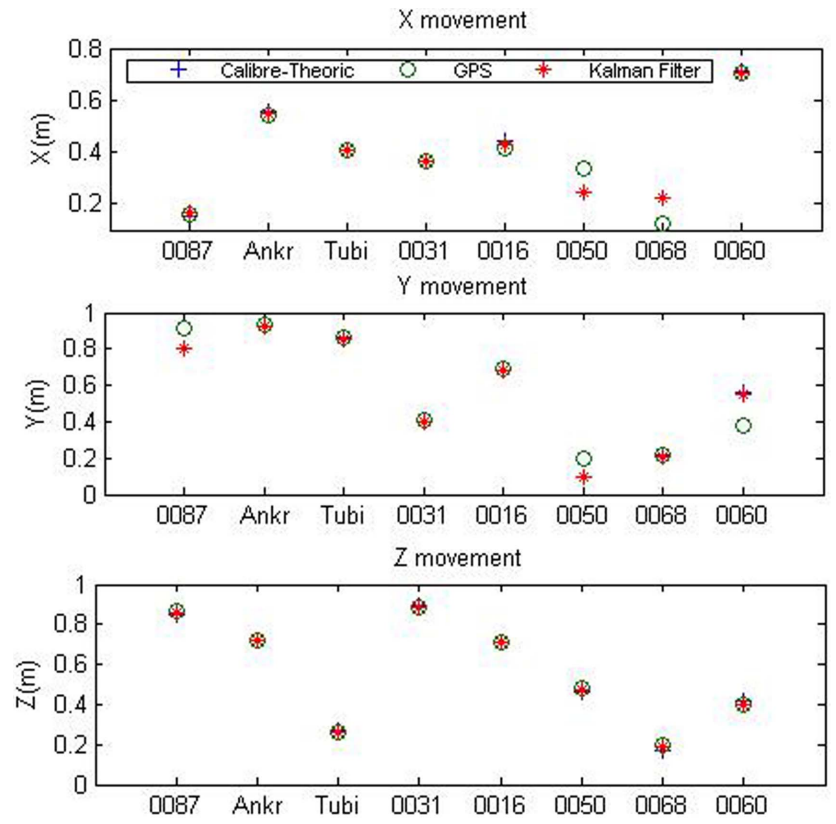

Fig. 7. Comparing the results of the GPS, Calibre-Theoric Model and Kalman Filter.

Horizontal and vertical movements given in Table 9 are retrieved as the total of the displacements calculated with the elastic half-space model and prediction result of the measurement-model differences.

The calculated values using this model produced more accurate results than the elastic half-space model. This is due to the use of a second approach to predict the unmodeled point movements close to the fault with the elastic half-space model. This approach reduced errors. In the elastic halfspace model, co-seismic deformations during earthquakes can be estimated. Additional movements occur at points as a result of post-seismic deformations after earthquakes.

With the created grid web in the study area, a known value of a coordinate before earthquake can be interpolated to find the coordinate of the same value after the earthquake. These coordinates during earthquake effect can be calculated using elastic half-space model (theoretical model) and post-seismic effects after earthquake can be calculated with griding theoretical model and GPS result differences. The closest results of real movement values can be obtained with addition of both method values. Total movement values can be added with pre-earthquake coordinates to find the post-earthquake coordinates sensitively.

\section{Application of Kalman Filtering which was adopted with calibrated theoretical model}

The retrieved point movements using method described in Sect. 4 were used in the prediction stage of the Kalman filter as a second filtering to calculate the post-earthquake point 
coordinates. The difference between this method and the method described above is that there is a change in the predicted state vector. The post-earthquake coordinates were predicted by adding the gridding result and the results obtained from the elastic half-space model to pre-earthquake point coordinates substituting Eq. (28) into Eq. (18) as follows

$\overline{\boldsymbol{x}}_{1}=\mathbf{T}_{0,1} \hat{\boldsymbol{x}}_{0}+\boldsymbol{d}_{\text {Calibre-Theoric }}+\mathbf{w}_{0}$

Post-earthquake coordinates are predicted by Eq. (29). Following the prediction stage, the filtering was applied with Gauss Markov model using the post-earthquake GPS data. Table 10 shows the displacements of points after the Kalman filtering.

As shown in Fig. 7, the model predicted coordinates are close the post-earthquake GPS measurements. The main reason for poor estimates of the elastic half-space model at Izmit and Düzce points is the continuing tectonic activities after the 1999 earthquake. The study results indicate that GPS and INSAR measurements right after earthquake are insufficient for parameter estimation of the elastic half-space model, and this can be improved by repeating measurements and using back modeling. Such measurements will apparently be costly and, therefore, prediction models can be used instead as proposed in this study.

\section{Conclusions}

In this work, deformation values were identified theoretically and experimentally for the earthquake occurred in the Marmara region of Turkey on 17 August 1999. Values retrieved from the theoretical model (elastic half-space model) and the experimental model (GPS measurements) were filtered with the Kalman filtering technique.

Values retrieved from the theoretical model (elastic halfspace model) and the experimental model (GPS measurements) indicate that position change differences get large in the area close to the fault zone. The reason for this is that the fault line is actually is not a line but a region and the elastic half-space model includes co-seismic position changes during the earthquake but not the post-seismic position changes after an earthquake. On the other hand, GPS measurements include co-seismic and post-seismic changes from 1998 to 2002.

To enhance the theoretical model thus increase the output quality of Kalman Filter, differences between theoric and experimental models has been modelled using Kriging model. As seen on Fig. 7, deformations occurred at the region after the earthquake has been calibred using Kriging gridding thus the Kalman Filter technique provided the best estimation values.

In applications where position changes, which is a result of earthquakes, are going to identified, if the measurements can be done within the smallest period after the earthquake
(Without the post-seismic effects) usage of Kalman Filter would fit better. If the after earthquake measurements do include post-seismic effects, it's suggested to model this with theoretical model and calibre before doing the filter process.

Acknowledgements. This study is funded by the Science and Research Projects Office of the Yildiz Technical University (YTU), Istanbul, Turkey, under YTU BAPK project numbered 24-05-0301. We wish to thank the YTU officers for their help during this project. We acknowledge the General Directorate of Land Registry and Cadastre of Turkey (TKGM) personnel for their invaluable support in providing data. B. King, B. Akpınar, Ö. Irmak and O. Yildiz are also acknowledged for their support and comments.

Edited by: M. Contadakis

Reviewed by: two anonymous referees

\section{References}

Aki, K. and Richards, P. G. : Quantitative Seismology Theory and Methods, W. H. Freeman and Co., San Francisco, 1980.

Aktuğ, B.: Elastik Yarı uzay modelleri ve Depremsel Koordinat Değişimlerine Dinamik Bir Yaklaşım, Harita Dergisi, Ankara, 2003.

Ayhan, M. E., Bürgmann, R., McClusky, S., Lenk, O., Aktuğ, B., Herece, E., and Reilinger, R. E.: Kinematics of the Mw_7.2, 12 November 1999, Düzce, Turkey Earthquake, Geophys. Res. Lett., 28, 367-370, 2001.

Bürgmann, R., Ayhan, M. E., Fielding, E. J., Wright, T. J., McClusky, S., Aktuğ, B., Demir, C., Lenk, O., and Türkezer, A.: Deformation during the 12 November 1999 Duzce, Turkey Earthquake, from GPS and InSAR Data, B. Seismol. Soc. Am., 92(1), 161-171, 2002.

Cannon, M. E., Schwarz, K. P., and Wong, R. V. C.: Kinematic Positioning with GPS and Analysis of Road Test, Proc. Fourth Int. Geodetic Symp. on Satellite Positioning, Austin, TX 28 April-2 May, 1986

Cohen, S. C.: Numerical Models of Crustal Deformation in Seismic Zones, Adv. Geophys., vol. 41, Academic Press, 1999.

Cressie, N. A. C.: The Origins of Kriging, Math. Geol., 22, 239252, 1990.

Çakır, Z.: Analysis of the crustal deformation caused by the 1999 Marmara earthquake sequence using synthetic aperture radar interferometry, Geological Engineering Dep., Institute of Sciences and Technology, Istanbul Technical University Département de Tectonique et Mécanique de la Lithosphère, Institut de Physique du Globe de Paris, 2003.

Donnellan, A., Hager, B. H., King, R. W., and Herring, T. A.: Geodetic Measurement of Deformation in the Ventura Basin Region, Southern California, J. Geophys. Res., 98(B12), $21727-$ $21739,1993$.

Ergintav, S., Bürgmann, R., McClusky, S., Çakmak, R., Reilinger, R. E., Barka, A., Lenk, O., and Gürkan, O.: Postseismic Deformation Near The Izmit Earthquake (08/17/1999, M=7.5) Rupture Zone, B. Seismol. Soc. Am., 92(1), 194-207, 2002.

Feigl, K. L., Sarti F., Vadon, H., McClusky, S., Ergintav, S., Bürgmann, R., Rigo, A., Durand, P., Massonet, D., and Reilinger, R.: Estimating slip distribution for the Izmit mainshock from 
coseismic GPS, ERS-1, RADARSAT, and SPOT measurements, Bull. Seism. Soc. Am., 92(1), 138-160, 2002.

Gelb, A.: Applied Optimal Estimation, The MIT Press, Cambridge, Massachusetts, 1974.

Herring, T. A.: GAMIT/GLOBK Kalman Filter VLBI and GPS Analysis Program Version 4.1, Massachusetts Institute of Technology, Cambridge, 1997.

Kalman, R. E.: A New Approach to Linear Filtering and Prediction Problems, J. Basic. Eng.-T. ASME, 83D, 95-108, 1960.

Kanamori, H.: The energy release in great earthquakes, J. Geophys. Res., 82, 2981-2987, 1977.

King, R. W. and Bock, Y.: Documentation for the MIT GPS Analysis Software: GAMIT, Mass. Inst. Tech, 1997.

Kuhlmann, H. and Pelzer, H.: Models of Deformation Analysis, Second Turkish-German Joint Geodetic Days, May, Berlin, 1997.

Kuhlmann, H.: Kalman-Filtering With Coloured Measurement Noise For Deformation Analysis, Proceedings, 11th FIG Symposium on Deformation Measurements, Santorini, Greece, 2003.

Lu, G. and Lachapelle, G.: Reliability Analysis for Kinematic GPS Position and Velocity Estimation, International Symposium on Kinematic Systems in Geodesy, Geomatics and Navigation, KIS 94 Banff, Canada, 30 August-2 September 2, 1994.

Okada, Y.: Surface Deformation Due to Shear And Tensile Faults In A Half-Space, Bull. Seism. Soc. Am., 75, 1135-1154, 1985.
Pelzer, H.: Application of Kalman and Wiener-Filtering on the Determination of Vertical Movements, The Symposium on Height Determination on Recent vertical Crustal Movements in Western Europe, September, Hannover, Determination of Heights and Height Changes, 1986.

Pelzer, H.: Anwendung der Kalman Filtertechnik auf die Deformationanalyse, X. Internationalen Kurs für Ingenieurvermessung, Kap. B4, Bonn, 1988.

Press, F.: Displacements, strains and tilts at tele-seismic distances, J. Geophys. Res., 70, 2395-2412, 1965.

Reilinger, R. E., Ergintav, S., Bürgmann, R., et al.: Coseismic and postseismic fault slip for the 17 August 1999, M_7.5, Izmit, Turkey earthquake, Science, 289, 1519-1524, 2000.

Salzmann, M.: MDB: A Design Tool for Integrated Navigation Systems, Kinematic Systems in Geodesy, Surveying and Remote Sensing Symposium, No. 107, Banff, Alberta, Canada, 10-13 September, 1990.

Salzmann, M.: Least Squares Filtering and Testing for Geodetic Navigation Applications, Netherlands Geodetic Commission, Publication on Geodesy, Number 37, 1993.

Schwarz, K. P.: Cannon, M. E., and Wong, R. V. C.: Comparison of GPS Kinematic Models for Determination of Position and Velocity Along Trajectory, Manuscr. Geod., 14, 1989.

Steketee, J. A.: On Volterra's dislocation in a semi-infinite elastic medium, Can. J. Phys., 36, 192-205, 1958.

Welsch, W. and Heunecke, O.: Terminology and Classification of Deformation Models, 9th International FIG-Symposium on Deformation Measurements, Olsztyn, 1999. 